\title{
CUT CONTROL OF LOGGING OPERATIONS
}

\author{
By W. L. Bubie
}

\author{
Chief Forester, Consolidated Paper Corporation, Limited
}

\section{INTRODUCTION}

I NDER the three common systems of Operating-Contractor, Jobber or

Company Camp-each have their favorable and unfavorable points.

It is for the Management to decide on the system which will be most advantageous for their requirements and, naturally, they will adopt methods of operating to take advantage of all the most favorable points and diminish to a minimum the unfavorable ones. The type and intensity of cut control has a direct bearing on the success of any system of operating. This paper deals mainly with the Contractor system of operating but with minor alterations could likewise be made applicable to the Jobber or Company camp system.

\section{OBJECT OF CUT CONTROL}

The object of cut control is:

1. To systematically cut over the forested area according to a predetermined rate as laid down in the Working Plan with the aim of creating a normal growing forest.

2. To ensure that the cutting is carried out according to forest regulations as laid down by the Government and Company.

3. To obtain maximum utilization.

4. To ensure adequate regeneration by leaving the cut over areas in the best possible condition for ultimately putting the forest on a sustained yield basis.

5. To ensure that the wood is scaled as accurately as possible.

\section{FOREST MAPS AND TIMBER ESTIMATES}

The basis of forest management is accurate forest maps and timber estimates and this is particularly true in connection with the cut control of logging operations. The first step is to obtain large scale maps (for field use) and small scale maps (for contract and administrative use) supported by detailed timber estimates for a main watershed. The scale of map required depends on the intensity of management and to a lesser extent on the topography. For all practical purposes, however, a scale $800^{\prime}$ to the inch for field use and 1 mile to $2^{\prime \prime}$ for contract and administrative use have been found to suit the requirements. The maps indicate the topography, such as lakes, streams, draws, cliffs, mountains and possible backhauls and show minor watersheds with sub-drainages. In addition, the maps show the timber stands divided as to age, type and volume per acre and each stand is supported by an individual detailed record giving description and timber volume. 


\section{PREPARATION OF TEN YEAR CUTTING PLANS AND ANNUAL LOGGING CONTRACT AREAS}

Having a sound foundation of forest maps and timber estimates, the next step is to lay down a ten year cutting plan. This consists of the coloring in of all mature and overmature timber according to types on the District Maps comprising a main watershed. The whole is then studied in detail and sub-divided into individual yearly cuts, keeping in mind the following: (1) Advisability of cutting overmature timber as early as possible; (2) Drive capacity of streams; (3) Average cost of annual cuts, etc.

The advantages of a ten year cutting plan are as follows:

1. It shows the location by yearly cuts of merchantable timbered area by types and the timber quantities, thus permitting a systematic planning of logging operations, having in view the watershed as a whole.

2. It permits an intelligent analysis and long term view of requirements, such as roads, depots, drive improvements, telephone lines, logging equipment and expensive machinery which can be provided for at the right time rather than some time after the immediate need for same has passed.

3. It permits the yearly costs of operations to be kept more uniform from year to year and at the same time serves as a basis for forecasting costs.

4. Most effective extension of roads can be located.

5. Depots, caches and camps can be more centrally located.

6. Mechanization of operations can be given full consideration.

With a ten year cutting plan as a guide, the immediate year's logging area is already determined. It stands to reason that more detailed information is required for an immediate logging contract area than is required in compiling a ten year cutting plan. Therefore, the area of the immediate cut must be care, fully checked over to determine and blaze the cutting boundaries. The timber estimates are checked, proposed sub-jobber areas indicated on map and all possible backhauls examined for reducing hauling costs.

In order to enable the Woods Manager to let out the logging contract areas intelligently and also to obtain the necessary order-in-council from the Quebec Government for cut by exception, the following details are required. Write-Up

1. Location; 2. Area, Timber Quantities and Per Cent. of Species; 3. Topography; 4. Forest Types and Age; 5. Average Composition by Inch Diameter Class by Types; 6 . Timber Estimates by Types; 
7. Reproduction by Species for each Type; 8. Description of Cutting and Hauling Conditions; 9. Cutting Methods; 10. Reason for Cutting Methods; 11. Landings; 12 . Improvements.

Timber Estimate Statement by Watershed Drainages or Jobbers' Areas

1. Haul Distance; 2. Trips per Day; 3. Total Contract Area; 4. Total Merchantable Area; 5. Total Cubic Feet; 6. Cubic Feet per Acre; 7. Cutting Conditions; 8. Hauling Conditions.

In addition to the above, logging contract maps, scale 1 mile-2", with mature and overmature timber colored according to types are furnished to all parties concerned, as well as cut and haul schedules.

On the basis of this information and any other details, which might be required, the cutting and hauling costs are determined and the area let for operating.

\section{CUT CONTROL OF OPERATIONS}

The contract having been let, the District Forester who, as a general rule, supervises the survey, the compilation of the ten year cutting plan and the preparation of logging contract area, is responsible for the inspection of the whole operation.

Organization

As far as possible, a unit of about 20,000 cunits, more or less, forms an inspection area. The personnel, under the direct supervision of the District Forester, necessary to handle the cut and haul inspection and the check scaling and locating of piles or rollways on an average sized area comprises:

1 Inspector; 1 Check Scaler; 1 Assistant Check Scaler.

Inspection of Cutting and Hauling

The purpose of the inspection work is:

To bring about an economical and uniform exploitation of the forest.

To have the cutting operations carried out according to the contract specifications and time schedule of cut and haul.

To follow Government and Company Forest Regulations and cooperate with the Government Representatives in enforcing them.

To see that the best interests are served by everyone on the cutting operations.

To secure the best possible forest regeneration.

To reduce the fire hazard by clean exploitation.

To ensure that the wood is scaled as accurately as possible.

To obtain production data and determine efficiency of the various jobbers.

To keep up to date maps and statements showing cut progress and timber still available. 
The question often arises as to the advantages of using Contractors', Jobbers' or Company Camps. The success of either of the three methods depends to a large extent on the type of man who runs the individual camps, subjobber, jobber or company. As to the control of cutting, so long as provisions have been made to deal with the respective method, there is no reason why equally good cut control will not result, regardless of the method of operating. The important factor is to give the Inspector sufficient responsibility and back him up in his decisions. The contractor and his sub-jobbers must be given to understand that the operations have to be carried out according to the regulations and it is the Inspector's duty to enforce these. Company Forest Regulations should provide penalties for all infractions not with the idea of obtaining compensation for infractions, but chiefly as a deterrent to prevent and discourage possible infractions.

A list of common infractions, for which provisions should be made, are as follows: Trees Cut Under Diameter Limit; Trees Cut Which Constitute Survey Lines; Stumps Cut Higher than Maximum Limit Set by Company or Government; Tops not Utilized; Trees Left Uncut; Trespass of Contract or Limit Boundary; Cutting of Young Timber; Wood Left Unskidded or Unhauled.

The duties of the Inspector comprise the following:

At the start of operations he must familiarize himself thoroughly with his area, by establishing tie points on the ground, such as survey lines, prominent topographical features, etc. He must reblaze all survey lines and stations passing through the area to avoid their being cut out, also ensure that all contract boundaries, if not natural, are well blazed. Each subjobber is instructed as to the forest regulations, what to cut, how to cut and location of cut. To aid in explaining and emphasizing the various items of Logging Contract and Company Forest Regulations, posters are set up in the various camps where the men can observe and study them.

As the operations get underway, if any sub-jobber is found to have too small or too large an organization, the contractor is advised and the situation followed up very closely until a suitable adjustment has been made. He must also supervise the piling, stamping and length of bolts to ensure himself of proper log making. Infractions of any part of the contract, including Government and Company Forest Regulations are noted and the sub-jobber advised of same. If an immediate improvement is not apparent, an infraction charge is made as a last resource. When a sub-jobber redresses an infraction after a charge has been made, a credit is given. The necessary forms are provided for Infraction Notices, Infraction Charges and Credits. In 
addition to this, a Permit Form is provided for to control the authorization of cuts outside the contract area. No authorization is given before the merits of the case are discussed by the proper authorities.

He has no authority to determine the landing space, as this comes under the jurisdiction of the Operating Department with whom the Inspector is in continual co-operation.

Each sub jobber is provided with time distribution forms for the recording of daily distribution of work for each man and horse on the job. The work classification is as follows:

\begin{tabular}{lll} 
& MeN & \\
Cutting_Salary & Slide & Miscellaneous \\
Cutting-Job & Piling & Cookery \\
Skid & Shovelling & Foreman \\
Haul & Portaging & Unemployed \\
Road & Camping & Travelling \\
& HoRses & \\
\multicolumn{1}{c}{ Skid } & & Portaging \\
$\quad$ Haul & & Camping \\
Hauling Trips & & Miscellaneous \\
Road & & Unemployed
\end{tabular}

The most suitable person in the camp is selected for keeping this distribution and the Inspector must check same to ascertain that the distribution is being properly and accurately kept up to date at all times.

At the end of each week, the Inspector visits each sub-jobber's camp and records all the data regarding timber quantity cut, hauled and number of men and horses employed during that week. This is summarized on a weekly cut inspection summary report and write-up.

These reports are forwarded to Forestry Headquarters, where they are further summarized by contract areas for all operations and made available to all those concerned, who are thereby continually informed as to the prog. ress being made.

Pediodically, a report is submitted to the Management, usually at the end of October, end of December and at the end of operations, including a small scale map of cutover area, a chart showing actual cut and haul plotted against cut and haul schedules, comparison of timber estimates by sub. drainages with actual timber cut, data on man-day and horse-day performance, scaling and check-scaling figures, as well as other items of interest.

Each Inspector is provided with a large scale map for field use in locating and checking roads and cutover areas which are thus mapped in as they 
are extended. The tie points as mentioned above are very important in this work. By keeping an up-to-date map of the cutover area, the Inspector is able to check up from time to time the reported quantities cut to date with the timber estimates. Further advantage is obtained by keeping the cutover area up-to-date during the cutting season in that, as soon as the cutting is finished, a final cutover map of the area is immediately available to balance off the timber inventories, thus maintaining up-to-date perpetual timber inventories.

Suitable report forms are completed by the Inspector before operations begin as to Camp Construction and Hygiene and during the life of the operations he reports on the Provincial Health Regulations. These are for the benefit of the Operating Department, to ensure that the regulations are followed.

"What is the use of all these reports?" In the first place, they serve useful purpose in keeping everyone concerned continually posted as to the actual situation on each contract area. Secondly, they give everyone an opportunity to analyze the operations and question any point which may appear doubtful. Thirdly, detailed data and written reports compel the Inspector to be $100 \%$ on his job and have complete control of the different phases of his work. Lastly, they ensure standardization in the methods of inspection, compiling data and reporting weekly on all operations.

\section{Cutting Methods}

The Quebec Government having been furnished with a detailed report and map of each Logging Contract Area, as stated above, the proposed cutting area is jointly examined in the field by a Government and Company Forest Engineer to decide on the cutting methods already recommended. Based on their findings, authorization is given by the Government to cut the mature and overmature timber only, at specified minimum diameters measured on the stump, one foot above the ground.

In the St. Maurice Watershed, except for a narrow strip at the lower end in the Tolerant Hardwood Zone, the balance of the watershed is located in the Central Transition Zone and the Northeastern Coniferous Zone. In the Transition Zone, for example, Spruce, Balsam and Jack Pine in the pure softwood types would be cut to a diameter of $5^{\prime \prime}$ on the stump. In the mixedwood type, White Spruce would be cut to 8 " and Black Spruce, Balsam and Jack Pine $5^{\prime \prime}$ on the stump, while in the hardwood type, Spruce would be cut to $10^{\prime \prime}$, Balsam to $7 "$ and Jack Pine to $12^{\prime \prime}$ on the stump. Naturally, the stump diameter is influenced by the amount of regeneration and the ability of the stand to regenerate itself. 
In determining the cutting methods, it must be borne in mind that they should of necessity be as simple as possible in keeping with forestry practice, so that the sub-jobbers and cutters will understand what trees to cut and what not to cut.

There is no question but that these methods can be improved upon, but for the present until further research is carried out, they are simple and yet make some provision for regeneration.

\section{Utilization}

To secure proper utilization, the following is observed:

All mature, overmature, Spruce, Balsam and Jack Pine trees are cut at a maximum stump height of 12 " and to a top diameter of $21 / 2$. . As the result of an educational campaign over a period of years, practically no difficulty is encountered in keeping stump heights below 12" and we estimate the average stump height to be around 9". The Quebec Government requires pulpwood species to be utilized to a top diameter of 3 ", but we call for $21 / 2 "$ in the inspection and accept in the scaling of the wood bolts even less than $21 / 2^{\prime \prime}$ in order to give the jobbers and cutters no reason for complaining that they cannot risk cutting small tops, if they are not to be accepted.

All wood is cut $4^{\prime}$ in length to obtain greater utilization of the forest, which in turn reduces to a minimum both waste and fire hazard and helps promote regeneration.

\section{Check Scaling}

In addition to his regular cut inspection duties, the Inspector is responsible for the check scaling. On each inspection unit a check scale crew locates $100 \%$ of all piles and rollways and check scales approximately $10 \%$ of all the wood. The Check Scaler receives his instructions from the Inspector as to what specifications have to be checked or located. The Checker's returns are turned over each night to the Inspector, who in turn makes the comparison with the Scaler's returns, and takes whatever steps are necessary to report differences to the Head Scaler for adjustment. Copies of all check scales are turned over to the Government Representative on the area and another copy is available for the Operators and Woods Manager.

\section{CONCLUSION}

This Company, through its Forestry Department, is working in close co-operation with the Quebec Forest Service, with a view of leaving the cutover areas in the best possible condition for ultimately placing the forest on a sustained yield basis. 